Pangarap ko, pangarap natin: The role of hope as a mediator between social support and school engagement among Filipino public school students

De Guzman, Mira Michelle Angeli

Ateneo de Manila University, Philippines (michellekdeguzman@gmail.com)

Macapagal, Ma. Elizabeth $\square$

Ateneo de Manila University, Philippines (mmacapagal@ateneo.edu)

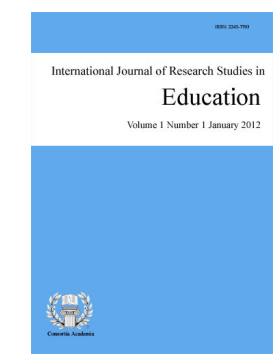

ISSN: 2243-7703 Online ISSN: 2243-7711

OPEN ACCESS

\title{
Abstract
}

Most students in the Philippines are enrolled in public schools, and yet conditions inside the classroom make it difficult for a student to stay engaged. Although there are many factors that contribute to school engagement, the current study looks at social support - particularly teacher support, parent support and peer help, as predictors of school engagement. The study also looks at hope as a mediating factor between this relationship, given that students are faced with adverse situations both in the school setting and in their communities. The study was conducted among Grade 6 students at a public elementary school in Quezon City. Regression analysis was conducted to look at the mediation between these variables. Based on the results of the study, hope serves as a partial mediator of the relationship between social support and school engagement. Results of the study have implications on factors on school outcomes, as well as school interventions on public schools in the Philippines.

Keywords: social support; school engagement; hope; Filipino; public school education 


\section{Pangarap ko, pangarap natin: The role of hope as a mediator between social support and school engagement among Filipino public school students}

\section{Introduction}

Most parents, especially Filipino parents, dream that their children will graduate from school in order to get a decent job to be able to support the family. Despite this, according to the 2018 Philippine Annual Poverty Indicators Survey (APIS), 9\% of youth are out of school (Philippine Statistics Authority, 2018) - and interestingly, one of the biggest reasons that explain this dropout rate is a 'lack of interest towards schooling' (p.1). This is unusual, especially since in the Philippines, education pursuit is seen as one of the more concrete paths to get out of poverty (Tuason, 2008). Furthermore, for Filipinos, education is valued, not necessarily to learn or gain knowledge, but for more practical reasons - such as to earn a degree, get a job, or pursue a career (Bernardo, 2003). This implies that while Filipino students have a high regard for education, this high regard is utilitarian; therefore, if there are other opportunities to get a job or earn money without finishing their education, Filipinos might be more inclined to do these.

Inside Filipino classrooms, however, students are also unmotivated and disengaged - most especially in the public schools. This was evident in a study conducted by Bernardo, Ganotice, and King (2015), where despite the fact that Filipino public school students generally had more positive affect towards school, they were less likely to express aspects of school engagement such as valuing for school and intention for further studying as compared to their private school counterparts. One consideration about the lack of engagement in public schools in the Philippines is that most of these students are faced with adverse experiences - whether it be due to their financial incapacities, lack of safety in their communities, or lack of sufficient resources for the schools. In these scenarios, it becomes difficult for students to stay fully motivated to learn when they have these experiences. Although these problems may be attributed to different factors in the country's complex education system, it seems that social and psychological factors may also play a role in affecting motivation for public school students.

\section{Literature review}

\subsection{School engagement}

While motivation is a cognition that cannot be directly observed, the Personal Investment Theory of Motivation makes sense of school engagement as a measure of motivation in the classroom context (Maehr \& Braskamp, 1986). School engagement, or educational engagement, is defined as the behavioral, psychological, and cognitive factors that determine how committed to learning a student is, and can even determine successful academic performance (Suh \& Suh, 2006). Given this, various variables are used to measure school engagement. Bernardo et al.'s study (2015) defined school engagement based on three variables - affect to school, intention for further education, and school valuing. On the other hand, McInerney, Dowson, and Yeung (2005) used affect to school and school valuing to measure school engagement; however, they also recognized that it is still possible that students have low affect to school but high motivation. Thus, for the current study, school engagement is measured based on the students' intention for further education and school valuing.

First and foremost, a student's value for his/her schooling is seen as an important tool in understanding what motivates a student to achieve, or even stay in school; however, this motivation is lessened when students feel that schooling does not improve their life chances (McInerney et al., 2005). On the other hand, a student's intention for further education plays a significant role in understanding school engagement. In a study conducted by Menon, Markadjis, Theodoropoulos, and Socratous (2016), intention for further studies was linked to the perceived rates of return, showing that intention for further education is an economic pursuit. Meanwhile, the 
intention to leave school was also seen as dependent on school factors such as teacher support and loneliness felt in the school (Frostad, Pijl, \& Mjaavatn, 2015). These two variables of school engagement were also seen as important in the study conducted by Bernardo et al. (2015), showing that private school students scored significantly higher on intention for further education and school valuing as compared to public school students. Thus, for public school, it seems that these two factors may indeed determine their level of school engagement.

\subsection{Personal investment and social support}

Aside from describing school engagement, the Personal Investment theory also posits that there are three aspects of school motivation that lead to school engagement - (a) facilitating conditions, which entail the perceived social support and influence available in the school; (b) sense of self, or how a student understands himself/herself; and (c) achievement goals, or the student's reason for taking on a certain task (Maerh \& Braskamp, 1986). However, in the context of a Filipino public school where resources may be limited, facilitating conditions, particularly social factors, may especially play a large role in keeping students engaged.

Of the various dimensions of facilitating conditions, social support, in particular, may play a role in school engagement. One study showed that social support was related to more positive school outcomes in general (Marques, Lopez, Fontaine, Coimbra \& Mitchell, 2015). Another study also showed that social support was related to satisfaction with school and positive academic values (Klem \& Connell, 2004). Social support is also being used as the basis for a number of effective school-based interventions in order to improve the social environment of the students, such as the First Things First model (Connell \& Klem, 2006) or the School Development Program (Comer, 1980) in the US.

In the school context, social support includes teacher support, parent support and peer support. Teacher support, first and foremost, is a factor that has a more direct relationship with school engagement, affecting the student at the cognitive, behavioral, and emotional level (Friedericks, 2004). This was also evident in a study conducted by Skinner and Belmont (1993), which shows the reciprocal relationship of teacher involvement with student engagement. Parent support, on the other hand, was also seen as a significant factor in predicting positive school outcomes. In fact, teacher and parent support as specially crucial during the students' adolescent phase (Wang \& Eccles, 2012). Although parent support was also seen as significant in a study by Ganotice and King (2013), the results of their study also showed that peer support actually had the strongest effect on school outcomes, especially at the adolescent age among a Filipino sample. This significance was expounded in a study by Wang and Eccles (2012), explaining that Filipino students at the adolescent age may view their schools, and their classmates, with a sense of belongingness, contributing to a stronger sense of satisfaction towards their school. Although it may seem that parent, teacher and peer support do have an effect on school outcomes, the results of Bernardo et al.'s study (2015) were in contradiction to these. In this study, the role of social support systems (i.e., teacher support, parent support, and peer help) did not have a significant effect on school engagement outcomes. Given the varied results of the effects of social support, it becomes especially important to understand further the role of social support on school engagement, especially among public school students in the Philippines.

\subsection{Hope theory}

Most Filipino students enrolled in public schools come from low-income families, so most of them are disadvantaged. Despite this, it seems that some of these students are able to rise above their challenging situation, finish school, and become successful in life. In the study conducted by Tuason (2008) that compared a poor family who remained poor, and a poor family who became rich, one of the differences that was identified between these two families was that the second group had goals, as well as plans to achieve them; while the first group did not. These goal-related cognitions are what Snyder, Irving, and Anderson (1991) would call hope.

Hope, according to Snyder et al. (1991), is described as a motivational state, composed of the interaction of 
agency, defined as goal-directed energy; and pathways, defined as the intention to meet one's goals. According to Snyder, there are also two ways to make sense of hope - dispositional hope, which measures a person's characteristic of hope (Snyder, Harris, Anderson, ... and Harney, 1991), and state hope, which measures a person's level of hope given a specific situation (Snyder, Sympson, Ybasco, Borders, Babyak, \& Higgins, 1996). In the context of more collectivistic cultures such as the Philippines, Bernardo (2010) also proposed an extension of the hope theory that explains dispositional hope as having either an internal or an external locus - taking into account that hope can be founded on belief towards others such as parents, peers, and spiritual beings. However, it is Bernardo's concept of internal hope, or Snyder's dispositional hope, that measures how an individual makes sense of his/her own capacity, rather than the capacity of others, to achieve his/her own goals. Given that this study aims to measure hope in the context of personal investment, it is internal hope, or dispositional hope, that will be utilized.

\subsection{Hope in the school context}

Developmentally, hope is shaped in a person both during early childhood up to early adolescence (Edwards, Ong, \& Lopez, 2007). A study by Snyder (2002) also shows that a child learns hope and other goal-oriented behaviors through social support systems - which endure throughout a person's pursuit of goals as he/she develops. While social support offers some explanation as to how hope is learned, a lack of perceived social support may also contribute to a loss of hope - especially for children who are neglected, abused or experience the loss of a parent. This was validated by Edwards et al. (2007) who showed a strong relationship between perceived support and high levels of hope. Furthermore, a study by Hagen, Myers and Mackintosh (2005) also showed that support from parents, peers, and teachers were significantly related to hope. In a study conducted among Canadian undergraduate students, relationships were also seen as the strongest impact on a a student's hope (Smith, Mills, Amundson, Niles, Yoon, \& In, 2014).

The same study by Smith et al. (2014) shows that for those who experience challenges in one's life, having hope can enable individuals to act on opportunities available to them. It seems that an individual's level of hope is also related to his/her ability in building resilience (Munoz, Brady, \& Brown, 2017). Specifically in the school context, however, hope is related to more positive school outcomes, and even citing its ability to facilitate reform (Newell \& Van Ryzin, 2009). In a study about profiles of hope in relation to school variables, students with high levels of hope also showed more adaptive school profiles - showing that having a high level of hope may lead the individual to engage in positive academic-related behaviors (Dixson, Worrell, \& Mello, 2017). Hope and school engagement were also seen as highly correlated, with school engagement working as the mediator between hope and academic achievement (Yoon, In, Niles, \& Amundson, 2015). In some school interventions, hope was also seen to improve school outcomes such as school engagement (Marques et al., 2015).

\subsection{Gaps in the literature}

Based on the literature review, although there have already been a number of studies conducted on school engagement, social support and hope, they are often studied as separate variables. Furthermore, although a number of these studies are conducted on Filipino samples, most of these studies are conducted among private school students. Thus, the results of these studies might not be generalizable to public school students whose experiences are unique from that of private school students. Aside from this, the studies aforementioned are mostly conducted among high school students. Research on students at the elementary level are often disregarded in studies about school engagement and hope - which shows a significant gap, especially since attitudes and beliefs about school are usually stronger at a younger age and are lessened as students' progress through the next stages of development (Wang \& Eccles, 2012). Finally, when considering factors in school outcomes among learners in the Philippines, hope is often disregarded as a factor. This also shows a significant gap, given that hope can play a huge role in school outcomes, especially for students from poorer households who are often challenged with difficult experiences. With these in mind, it seems that there is a need to rethink the model of personal investment, especially in the context of early adolescence among public school students in 
the Philippines.

\subsection{Hope as a mediator of personal investment}

The research problem that the current study would like to investigate is the following: What is the role of hope in the context of social support and school engagement of public school students? While the hope can be learned through social support, it seems that hope can also help propel individuals towards goals which, in the context of school, can manifest through school engagement. In this regard, for the current study, we hypothesize that a student's level of hope can serve as a mediator between perceived social support and school engagement.

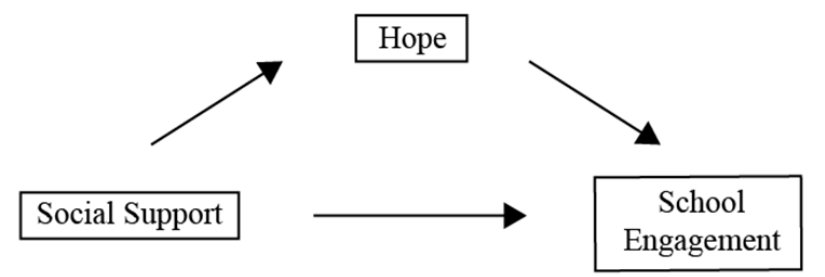

Figure 1. Proposed mediation model of hope as a buffer of social support and school engagement.

In particular, we first consider the degree to which social support predicts school engagement. A number of studies have already shown the strong relationship between social support and school engagement (Skinner \& Belmont, 1993; Wang \& Eccles, 2012), even in the Philippine setting (Bernardo et al., 2015; Ganotice \& King, 2013; King \& Ganotice, 2013); therefore, this hypothesis is plausible. Second, we hypothesize that hope is also a significant predictor of school engagement. As previously mentioned, having high hope has a lot of positive effects on school outcomes, including school engagement (Yoon et al., 2015). Finally, we hypothesize that hope can serve as a mediator between social support and school engagement. Although there are no studies in the Filipino public school context that have considered this mediating relationship, one study conducted among Turkish middle students shows that hope acts as a mediator between social support and school burnout (Gungor, 2019) - showing promise that this relationship between social support and hope may also be applied to school engagement. Furthermore, given that hope is taught through social support systems (Snyder, 2002) and can also contribute to behaviors of school engagement (Smith et al., 2014; Yoon et al., 2015), it seems that it is plausible that one's sense social support can affect one's levels of hope, which, in turn, can also affect one's sense of school engagement.

\section{Methodology}

\subsection{Research design}

To address this question of a hope-based model for school engagement, the current study made use of pragmatism as the research paradigm. Thus, a quantitative correlational research design was utilized in order to understand the relationship of social support and school engagement, with hope as a mediating factor. The data were obtained using pencil-and-paper surveys. The data were then encoded, and the data were analyzed using mediation analysis through SPSS.

\subsection{Participants}

Participants included 34 male and 85 female Grade 6 Filipino students aged 12 to 17, from a public school in Quezon City, Metro Manila with a total population of 6,258 students. The school was chosen based on purposive sampling to represent public schools in Quezon City. The participants come from low to middle SES. While class sections for this school are heterogeneous (or are not classified based on school performance), sections that participated in the current study were based on the recommendations of the School Principal and the Grade Level Coordinator. Participation in the study was voluntary, which was emphasized through the consent 
form, and was also reiterated by the classroom advisers to their students, so as to avoid coercion.

\subsection{Data collection measures}

For this study, items from the Filipino version of the Facilitating Conditions Questionnaire (Ganotice et al. 2013) were utilized to measure teacher support, peer support, parent support and school engagement among Filipino grade school students. Previous studies have already confirmed the structural validity of this scale (McInerney et al., 2005) and its translation (Ganotice, Bernardo, \& King, 2013) through confirmatory factor analysis procedures. In consideration of the age of the participants, some questions from these scales were omitted - particularly items on negative parent influence, negative peer influence, pride from others, intention to leave school and affect - in order to make it easier for the participants to answer the questionnaires.

On the other hand, in order to measure a student's behaviors of his/her own capacity to achieve goals and the pathways to achieve them, items on internal locus of hope from Bernardo's Locus of Hope Scale (2010) were utilized. Although this measure of hope was based on the Dispositional Hope Scale (Snyder et al., 1991), one item from Snyder's scale was removed and another item was edited in the internal Locus of Hope scale order to make the items more appropriate for a Filipino sample. Aside from this, while the scales were in English, we translated each item to Filipino so that the items will be more easily understood by the participants of the study.

Social support - The means on the items on parent support, teacher support, and peer help from the Facilitating Conditions Questionnaire (McInerney et al., 2005), were utilized in order to measure social support. This was scored on a 5-point Likert scale ranging from $1=$ strongly disagree to $5=$ strongly agree. Dimensions of this scale include parent support ( 3 items, e.g., "My mother helps me with my school work."; $\alpha=.74$ ), teacher support (6 items, e.g. "Teachers are positive to me at school."; $\alpha=.65$ ), and peer help (5 items, e.g., "Some of my friends help me with my school work."; $\alpha=.73$ ).

School engagement - In order to understand school engagement, the means of items for school engagement were utilized from Facilitating Conditions Questionnaire. This was also scored on a 5-point Likert scale ranging from $1=$ strongly disagree to $5=$ strongly agree. Dimensions of the scale include intention for further education scale (5 items, e.g., "I intend to go on to college or university"; $\alpha=.84$ ), and the school valuing scale (9 items, e.g., "Education is important for me to get a job"; $\alpha=.86$ ). This was scored on a 5-point Likert scale ranging from 1 = strongly disagree to $5=$ strongly agree.

Hope - In order to measure hope, items for internal locus of hope from the Locus of Hope Scale developed by Bernardo (2010) as an extension of Snyder's Dispositional Hope Scale (Snyder et al., 1991) was administered to the participants. The scale includes 8 items which are scored on a 6-point Likert scale from $1=$ definitely false to $6=$ definitely true. This subscale includes 8 items (e.g. "I can think of many ways for me to get out of a problem" $\alpha=.71)$.

\subsection{Data collection procedure}

We were able to obtain ethics clearance from the Ateneo University Research Ethics Office to conduct the study. Afterwards, permits were obtained from the school administration where the study was to be conducted. A pilot test was then conducted among 40 Grade 6 students in the school to test and improve on the questionnaires utilized for the study. After the pilot test, participants were then recruited from the rest of the Grade 6 students for the actual study. Following informed consent and assent procedures, a paper-and-pencil test for the three scales were administered to the participating classes. Following the administration of the test, tokens were provided to the students who participated in the study. An analysis of the results was done through SPSS.

\subsection{Data analysis procedure}

The data were log transformed to correct for skewness, but the raw means, standard deviations and ranges of

30 Consortia Academia Publishing (A partner of Network of Professional Researchers and Educators) 
Role of hope as a mediator between social support and school engagement among Filipino public school students the main variables were reported to accommodate for interpretability. The log transformed data were then analyzed. The Cronbach's alpha and the Pearson R coefficients were obtained to measure reliability of each scale, while the scales used were already tested for validity from previous studies (Bernardo, 2010; Ganotice et al., 2013). Afterwards, ANOVA was used to validate the significance of social support and sense of hope on school engagement. Finally, to test for the indirect, direct, and total effects of hope as a mediator of social support towards school engagement, mediated regression analysis through PROCESS (Hayes, 2017) was conducted, based on the steps laid out by Baron and Kenny (1986). Bootstrapping procedures were also conducted to validate the significance of the indirect effects.

\section{Results}

Table 1 shows the means, standard deviations, Pearson $\mathrm{r}$ correlations, as well as the alpha coefficients of each of the variables. Generally, the scores for social support $(M=4.07, S D=.55)$, hope $(M=4.39, S D=.79)$, and school engagement $(M=4.47, S D=.49)$ were high, showing that the participants had high perceived social support, could be considered high hopers, and had high levels of school engagement. On the other hand, Table 2 shows the correlation between variables. Based on the results, it seems that social support was significantly correlated with hope $(r(117)=.27, p<.01)$, hope was significantly correlated with school engagement $(r(117)$ $=.36, p<.01)$, and social support was significantly correlated with school engagement $(r(117),=.51, p<.01)$. Looking at the sub-variables under the three main variables, however, almost all were significantly correlated at the $p<.05$ level. Only two relationships did not show a significant correlation - teacher support with hope pathways and parent support with hope pathways. Aside from this, reliability coefficients were also identified to determine the internal consistency of the scales. With the exception of Hope - Agency ( $\alpha=0.56$ ), values of the Cronbach's alpha for the scales ranged from 0.62 to 0.89 , signifying internal consistency.

\section{Table 1}

Cronbach's alpha and correlation coefficients between social support, hope, and school engagement $(N=119)$

\begin{tabular}{|c|c|c|c|}
\hline Variables & Alpha & $M$ & $S D$ \\
\hline 1. Social support & .85 & 4.07 & .55 \\
\hline a. Teacher support & .65 & 4.26 & .67 \\
\hline b. Parent support & .74 & 4.02 & .61 \\
\hline c. Peer help & .73 & 3.94 & .70 \\
\hline 2. Hope & .71 & 4.39 & .79 \\
\hline a. Pathways & .62 & 4.16 & .98 \\
\hline b. Agency & .56 & 4.53 & .84 \\
\hline 3. School engagement & .89 & 4.47 & .49 \\
\hline a. School valuing & .86 & 4.42 & .68 \\
\hline b. University Intention & .84 & 4.50 & .47 \\
\hline
\end{tabular}

\section{Table 2}

Correlation coefficients between social support, hope, and school engagement

\begin{tabular}{|c|c|c|c|c|c|c|c|c|c|}
\hline Variables & $1 \mathrm{a}$ & $1 \mathrm{~b}$ & $1 \mathrm{c}$ & 2 & $2 \mathrm{a}$ & $2 b$ & 3 & $3 a$ & $3 \mathrm{~b}$ \\
\hline 1. Social support & $.88^{* *}$ & $.78 * *$ & $.83 * *$ & $.27 * *$ & $.23^{*}$ & $.25^{* *}$ & $.50 * *$ & $.38 * *$ & $.50 * *$ \\
\hline a. Teacher support & - & $.64 * *$ & $.53 * *$ & $.21 *$ & .17 & $.20^{*}$ & $.48^{* *}$ & $.40 * *$ & $.46^{* *}$ \\
\hline b. Parent support & & - & $.47 * *$ & $.20^{*}$ & .13 & $.20^{*}$ & $.47 * *$ & $.32 * *$ & $.50 * *$ \\
\hline c. Peer help & & & - & $.26^{* *}$ & $.23^{*}$ & $.23^{*}$ & $.32 * *$ & $.23 * *$ & $.33 * *$ \\
\hline 2. Hope & & & & - & $.82 * *$ & $.92 * *$ & $.36^{* *}$ & $.35 * *$ & $.31 * *$ \\
\hline a. Pathways & & & & & - & $.53 * *$ & $.25^{* *}$ & $.22 *$ & $.23 *$ \\
\hline b. Agency & & & & & & - & $.36^{* *}$ & $.37 * *$ & $.29 * *$ \\
\hline 3. School engagement & & & & & & & - & $.87 * *$ & $.92 * *$ \\
\hline a. School valuing & & & & & & & & - & $.60 * *$ \\
\hline b. University Intention & & & & & & & & & - \\
\hline
\end{tabular}




\subsection{Mediation analysis}

Table 3, on the other hand, shows the results of the mediation analysis. These results show that social support explained a significant proportion of variance in social engagement $\left(F(1,117)=40.04, p<.01, R^{2}=0.25\right)$, wherein social support significantly predicted school engagement $(\beta=.50, \mathrm{t}(117)=6.33, p<.01)$. Furthermore, when hope was entered into the model $\left(F(2,116)=26.07, p<0.01, R^{2}=0.31\right)$, the total effect between social support and school engagement was lessened, but nonetheless remained significant $(\beta=.24, \mathrm{t}(116)=5.51, p<.01)-$ confirming the hypothesis that hope is a mediator between social support and school engagement. Meanwhile, the standardized indirect effects were significant at $(.26)(.24)=.50$. The regression analysis also showed that social support and hope together explained a significant variance of school engagement $\left(F(1,117)=8.82, p<.01, R^{2}=\right.$ $0.07)$, wherein social support predicted hope $(\beta=0.26, \mathrm{t}(117)=2.97, p<.01)$ and hope predicted school engagement $(\beta=.24, \mathrm{t}(116)=3.05, p<.01)$. These results confirm that hope serves as a partial mediator between social support and school engagement. Furthermore, the significance of the indirect effects of the model were tested through bootstrapping procedures. For each 5,000 bootstrapping samples, at the 95\% confidence interval, the bootstrapped indirect effect was .0572 , ranging from $.0076, .1285$ - confirming the significance of the indirect effects of the model.

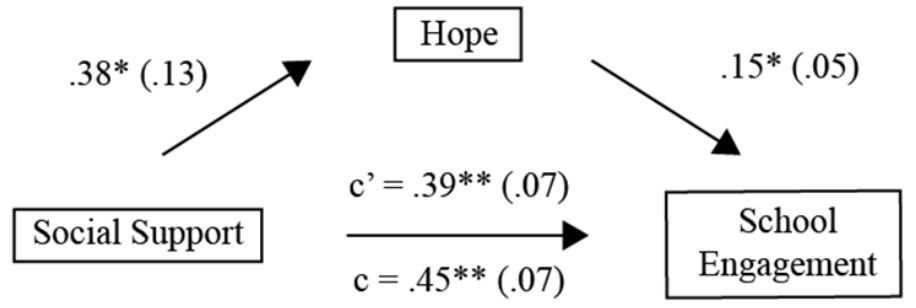

Figure 2. Model of the mediating effect of hope on the relationship between social support and school engagement. The effects presented in this model are unstandardized, while standard errors are shown in parentheses. The value of c represents the total effect of social support on school engagement, while the value of c' represents the direct social effect of social support on school engagement. *p<.05, ***p<.001.

Table 3

Hope as a mediator

\begin{tabular}{llccc}
\multicolumn{1}{c}{ Models } & $\beta$ & Std. error & $t$ & $p$ \\
\hline Step 1 Social support and school engagement & .44 & .07 & 5.51 & $.0029^{*}$ \\
Step 2 Social support and hope & .26 & .13 & 2.97 & $.0036^{*}$ \\
Step 3 Social support, hope, and school engagement & .50 & .07 & 6.33 & $.0000^{*}$ \\
\hline Note *p<05.
\end{tabular}

Note. ${ }^{*} p<.05$.

\section{Discussion}

\subsection{Re-examining the literature}

The study was conducted in order to understand the role of hope as a mediator of social support in predicting school engagement among Filipino public school students. In terms of correlations, findings of the study show that social support, hope and school engagement are correlated with each other, reaffirming that there is indeed a relationship among these three variables (Van Ryzin, 2011). Breaking it down to its subvariables, however, hope-pathways was not seen to be correlated with teacher support and parent support. As mentioned previously, hope-pathways in particular deal with thoughts about means to achieve a goal. Although this relationship between hope-pathways, parent support and teacher support are in contrast with most studies on the relationship of social support with hope (Hagen et al., 2005), one possible explanation for this is the saliency of the student's relationship with his peers, especially at the early adolescent stage (Wang \& Eccles, 2012). At this 
developmental stage, it is possible that students are not looking to their parents and teachers to figure out pathways to attain a goal; instead, this conversation happens with their peers. Looking at internal consistency, on the other hand, the results of the reliability analysis show that items on social support and school engagement are significant, reaffirming Ganotice et al.'s study on the validity of the Filipino translation of the Facilitating Conditions Questionnaire (2013). However, the low reliability coefficient score for the Internal Hope Scale (Bernardo, 2010), particularly hope-agency, may be associated with the translation of the scale into the Filipino language and for younger samples, which is a limitation of this study.

Looking at the significant results of the regression analysis, it seems that our understanding of Personal Investment theory can be expanded in the context of the Filipino public school setting, such that social support also works through hope in order to increase the students' level of engagement in school. This implies that while the perceived social support that a student receives helps predict his/her level of engagement, some aspect of social support also works to increase a student's level of hope in his/her own capacity and pathways to achieve goals. This way of thinking, then, helps increase his/her levels of school engagement further. This significant mediation effect is consistent with the study conducted by Gungor (2019), showing that hope mediates the relationship between social support and factors on school motivation such as burnout; or in this case of this current study, school engagement.

In terms of effects of the model, social support is a significant predictor of school engagement. While these results validate an aspect Personal Investment theory showing that social support plays a role in school engagement (Maehr \& Braskamp, 1986), these findings affirm the studies on peer support predicting positive school outcomes, such as school engagement (Wang \& Eccles, 2012; Ganotice \& King, 2013). Furthermore, the results of the study are in contrast with Bernardo et al.'s study (2015) that shows that social support did not have a significant effect on school engagement on public school students. Bernardo's study had high school students as a sample, which might imply that social support systems for public school students play a more significant role at a younger age. In terms of indirect effects, on the other hand, social support was also seen as a significant predictor of hope, showing that having higher levels of social support can increase levels of hope (Hagen et al., 2005; Dixson et al., 2017). Furthermore, hope was seen as a predictor of school engagement (Marques et al., 2015), showing that an individual's sense of hope has implications on the school setting; in fact, it can even predict a student's level of engagement in school.

\subsection{Implications for educational practice}

Findings from this study encourage us to rethink how we understand Philippine public school education. One of the new contributions of the current study is the relevance of hope in the school engagement, or even school outcomes in general, in public school student learning. Aside from this, the results of the study also goes to show that for these students, hope can be learned through his/her social support systems; which also contributes to his/her level of engagement in school. In terms of educational practice, these findings have a number of implications on pedagogical content such as curriculum design or classroom management strategies that can be founded, not just on social support but on hope as well, in order to encourage school engagement. Aside from these, it seems that this model of school engagement and motivation may also have practical implications for school dropouts. Based on the results of the study, it seems that utilizing social support and hope may help encourage more students to get engaged in school, which may lessen behaviors that are precursors to dropping out, such as skipping school, cutting class, or suspension. In fact, increasing school engagement may also lead to other positive school outcomes such as academic achievement (Fredricks, 2004).

The current study may also have implications for education policy and reform. The results of the study show much potential in designing school interventions to tackle school engagement through social support, through hope, or even both. Previous studies have already validated the significance of social support-based interventions (Comer, 1980; Institute for Research and Reform in Education, 2003), and hope-based interventions (Marsay, Scioli \& Omar, 2018) in order to improve school outcomes. These programs, along with the results of the current 
study, emphasize further that interventions with hope or with social support as the focus can be effective in increasing school engagement for public school students. Aside from this, the findings of this study also show some evidence in encouraging the use of positive discipline in the classroom. Rather than a more authoritarian approach that is being utilized in some public school classrooms today, the results of the study also show that teachers, parents and peers can take part in teaching more positive competencies, such as hope and social support, to the students, in order to keep them engaged in learning.

\subsection{Limitations and future studies}

Some limitations of the study include the fact that the study was only conducted among Grade 6 students in one public school in Quezon City - which means that the study may not be generalizable to students in other settings. In terms of the scales on the other hand, the original Facilitating Conditions Questionnaire (McInerney et al., 2005), was too lengthy, especially with the age of the participants in mind; thus, some items had to be omitted. For the Hope Scale (Bernardo, 2010), however, the complexity of items was also a limitation, making the scale difficult to translate.

For future studies, a qualitative study can also be conducted to complement the current study. Qualitative methods may allow for a deeper understanding of student experiences, especially for variables that are more latent such as social support, hope, and school engagement. Another recommendation would be to expand the study in order to unpack other aspects of the Personal Investment Theory, such as sense of self or achievement goals. Given that only the social support aspect of facilitating conditions was utilized for this study, these other aspects of motivation may provide a clearer picture of school engagement. Finally, it would also be interesting to expand the idea of hope to take into account Bernardo's external loci of hope (2010) - particularly towards parents, peers, and even spirituality. This extension of hope theory may provide a deeper understanding of the relationship of social support, hope and school engagement, especially in the context of the Filipino public school system.

\section{Conclusion}

A student's level of school engagement has many implications, not just in a student's school life, but on his/her future as well. Despite this, in a country where education is highly valued, many students are unmotivated and disengaged. Thus, the current study attempted to understand how school engagement works in the context of a public school, and how hope can play as a mediator, especially for public school students who are faced with adverse situations. The findings of this study show that both social support and hope predict school engagement, and that some aspect of hope actually works through social support to predict student engagement. Although the odds are stacked against students in public schools, this study shows that for these students, there is still hope.

Acknowledgements - I would like to thank Zenaida Mallilin, Adelfa Lara and Jaime Mejia for facilitating the data gathering activities, as well as the Office of the Associate Dean for Graduate Programs for the Thesis Scholarship. Approval from the Faculty of the Department of Psychology, School of Social Sciences, Ateneo de Manila University was obtained on the 20th of March, 2020.

\section{References}

Baron, R. M., \& Kelly, D. A. (1986). The moderator-mediator variable distinction in social psychological research: Conceptual, strategic, and statistical considerations. Journal of Personality and Social Psychology, 51(6), 1173-1182. https://doi.org/10.1037/0022-3514.51.6.1173

Bernardo, A. B. I. (2003). Do Filipino youth really value education? Exploring Filipino adolescents' beliefs about the abstract and pragmatic value of education and its relationship to achievement goals and 
Role of hope as a mediator between social support and school engagement among Filipino public school students learning strategies. Philippine Journal of Psychology, 26, 49-67.

Bernardo, A. B. I. (2010). Extending hope theory: Internal and external locus of trait hope. Personality and Individual Differences, 49, 944-949. https://doi.org/10.1016/j.paid.2010.07.036

Bernardo, A., Ganotice, F., \& King, R. (2015). Motivation gap and achievement gap between public and private high schools in the Philippines. Asia-Pacific Education Researcher, 24(4), 657-667. https://doi.org/10.1007/s40299-014-0213-2

Comer, J. (1980). School power: Implications of an intervention project. New York: Free Press.

Connell, J. P., \& Klem, A. M. (2006). First things first: A framework for successful secondary school reform. New Directions for Youth Development, 2006(111), 53-59. https://doi.org/10.1002/yd.182

Dixson, D. D., Worrell, F. C., \& Mello, Z. (2017). Profiles of hope: How clusters of hope relate to school variables. Learning and Individual Differences, 59, 55-64. https://doi.org/10.1016/j.lindif.2017.08.011

Edwards, L. M., Ong, A. D., \& Lopez, S. J. (2007). Hope measurement in Mexican American youth. Hispanic Journal of Behavioral Sciences, 29(2), 225-241. https://doi.org/10.1177/0739986307299692

Fredricks, J. A., Blumenfeld, P. C., \& Paris, A. H. (2004). School engagement: Potential of the concept, state of the evidence. Review of Educational Research, 74(1), 59-109. https://doi.org/10.3102/00346543074001059

Frostad, P., Pijl, S. J., \& Mjaavatn, P. E. (2015). Losing all interest in school: Social participation as a predictor of the intention to leave upper secondary school early. Scandinavian Journal of Educational Research, 59, 110-122. https://doi.org/10.1080/00313831.2014.904420

Ganotice, F. A., \& King, R. B. (2013). Social influences on students' academic engagement and science achievement. Psychological Studies, 59(1), 30-35. https://doi.org/10.1007/s12646-013-0215-9

Ganotice, F. A., Bernardo, A. B. I., \& King, R. B. (2013). Adapting the facilitating conditions questionnaire (FCQ) for bilingual Filipino adolescents: Validating English and Filipino versions. Child Indicators Research, 6, 237-256. https://doi.org/10.1007/s12187-012-9167-1

Gungor, A. (2019). Investigating the relationship between social support and school burnout in Turkish middle school students: The mediating role of hope. School Psychology International, 40(6), 581-597. https://doi.org/10.1177/0143034319866492

Hagen, K., Myers, B., \& Mackintosh, V. (2005). Hope, social support, and behavioral problems in at-risk children. The American Journal of Orthopsychiatry, 75, 211-219. https://doi.org/10.1037/0002-9432.75.2.211

Hayes, A. F. (2017). Introduction to mediation, moderation, and conditional process analysis: A regression-based approach. The Guilford Press.

Institute for Research and Reform in Education [IRRE]. (2003). First things first: A framework for successful school reform. IRRE.

King, R. B., \& Ganotice Jr., F. A. (2013). Student motivation as hierarchical and multidimensional: Cross-cultural validation of personal investment theory in the Philippines. Universitas Psychologica, 12(3), 1-32. https://doi.org/10.11144/Javeriana.UPSY12-3.smhm

Klem, A., \& Connell, J. (2004). Relationships matter: Linking teacher support to student engagement and achievement. Journal of School Health, 74(7), 262-273. https://doi.org/10.1111/j.1746-1561.2004.tb08283.x

Maehr, M. L., \& Braskamp, L. (1986). The motivation factor: A theory of personal investment. Lexington Books. Marques, S. C., Lopez, S. J., Fontaine, A. M., Coimbra, S., \& Mitchell, J. (2015). How much hope is enough? Levels of hope and students' psychological and school functioning. Psychology in the Schools, 52, 325-334. https://doi.org/10.1002/pits.21833

Marsay, G., Scioli, A., \& Omar, S. (2018). A hope-infused future orientation intervention: A pilot study with juvenile offenders in South Africa. British Journal of Guidance \& Counselling, 46(6), 709-721. https://doi.org/10.1080/03069885.2018.1480011

McInerney, D. M., Dowson, M., \& Yeung, A. (2005). Facilitating conditions for school motivation: Construct validity and applicability. Educational and Psychological Measurement, 65, 1046-1066. https://doi.org/10.1177/0013164405278561 
Menon, E. M., Markadjis, E., Theodoropoulos, N., \& Socratous, M. (2016). Influences on the intention to enter higher education: The importance of expected returns. Journal of Further and Higher Education, 41(6), 831-843. https://doi.org/10.1080/0309877X.2016.1188897

Munoz, R. T., Brady, S., \& Brown, V. (2017). The psychology of resilience: A model of the relationship of locus of control to hope among survivors of intimate partner violence. Traumatology, 23(1), 102-111. https://doi.org/10.1037/trm0000102

Newell, R. J., \& Van Ryzin, M. (2009). Assessing what really matters in schools: Creating hope for the future. Lanham, MD: Rowman and Littlefield.

Philippine Statistics Authority. (2018). Nine percent of Filipinos aged 6 to 24 years are out of school. Retrieved from

https://psa.gov.ph/content/nine-percent-filipinos-aged-6-24-years-are-out-school-results-2017-annual-p overty-indicators

Skinner, E. A., \& Belmont, M. J. (1993). Motivation in the classroom: Reciprocal effect of teacher behavior and student engagement across the school year. Journal of Educational Psychology, 85, 571-581. https://doi.org/10.1037/0022-0663.85.4.571

Smith, B. A., Mills, L., Amundson, N. E., Niles, S., Yoon, H. J., \& In, H., 2014. What helps and hinders the hopefulness of post-secondary students who have experienced significant barriers. The Canadian Journal of Career Development, 3, 59-74.

Snyder, C. R., Harris, C., Anderson, J. R., Holleran, S. A., Irving, L. M., Sigmon, S. X., ... Harney, P. (1991). The will and the ways: Development and validation of an individual-differences measure of hope. Journal of Personality and Social Psychology, 60(4), 570-585. https://doi.org/10.1037/0022-3514.60.4.570

Snyder, C. R., Irving, L. M., \& Anderson, J. R. (1991). Hope and health. In C. R. Snyder \& D. R. Forsyth (Eds.), Handbook of social and clinical psychology: The health perspective (Vol. 162, pp. 285-305). Elmsford, NY, US: Pergamon Press.

Snyder, C. R., Sympson, S. C., Ybasco, F. C., Borders, T. F., Babyak, M. A., \& Higgins, R. L. (1996). Development and validation of the State Hope Scale. Journal of Personality and Social Psychology, 70, 321-335. https://doi.org/10.1037/0022-3514.70.2.321

Suh, S., \& Suh, J. (2006). Educational engagement and degree attainment among high school dropouts. Educational Research Quarterly, 29(3), 11-20.

Synder, C. R. (2002). Hope theory: Rainbows in the mind. Psychological Inquiry, 13, 249-275. https://doi.org/10.1207/S15327965PLI1304_01

Tuason, M. G. (2008). Those who were born poor: A qualitative study of Philippine poverty. Journal of Counseling Psychology, 55(2), 158-171. https://doi.org/10.1037/0022-0167.55.2.158

Van Ryzin, M. J. (2011). Protective factors at school: Reciprocal effects among adolescents' perceptions of the school environment, engagement in learning, and hope. Journal of Youth Adolescence, 40, 1568-1580. https://doi.org/10.1007/s10964-011-9637-7

Wang, M. T., \& Eccles, J. S. (2012). Social support matters: Longitudinal effects of social support on three dimensions of school engagement from middle to high school. Child Development, 83(3), 877-895. https://doi.org/10.1111/j.1467-8624.2012.01745.x

Yoon, H. J., In, H., Niles, S. G., \& Amundson, N. E. (2015). The effects of hope on student engagement. The Canadian Journal of Career Development, 14(1), 34-45. 